\title{
LA DEROGATIO FORI EN LA LEY ORGÁNICA DEL PODER JUDICIAL
}

\author{
Beatriz CAmpuzano DíaZ*
}

\begin{abstract}
SUMARIO: 1. INTRODUCCIÓN.-2. LA ADMISIBILIDAD DE LA DEROGATIO FORI EN NUESTRO SISTEMA AUTÓNOMO.-2.1. Antecedentes.-2.2. La admisibilidad de la derogatio fori tras la Ley Orgánica 7/2015, de 21 de julio, por la que se modifica la Ley Orgánica 6/1985, de 1 de julio, del Poder Judicial.-3. LA APLICACIÓN SUBSIDIARIA DE LA LOPJ.-3.1. El Reglamento (UE) núm. 1215/2012.-3.2. Otros instrumentos internacionales.-4. EL RÉGIMEN DE LA DEROGATIO FORI EN LA LOPJ.-4.1. Naturaleza de los foros derogables y materias en relación con las que se admite la derogatio fori.-4.2. El acuerdo tiene que celebrarse con ocasión de una determinada relación jurídica en favor de un tribunal extranjero.- 4.3. La validez formal del acuerdo.- 4.4. La validez material del acuerdo.-4.5. Tratamiento procesal.-5. CONCLUSIONES.
\end{abstract}

\section{INTRODUCCIÓN}

1. Los acuerdos de sumisión expresa presentan indudables ventajas. En primer lugar, las partes ganan en previsibilidad y seguridad jurídica. En un mundo jurídicamente fragmentado, donde la diversidad de normas nacionales de competencia judicial internacional permitiría llevar el litigio a los tribunales de un país u otro, las partes pueden fijar de antemano el tribunal que será competente, evitando así quedar a merced de las estrategias procesales oportunistas que pudiera desarrollar una de ellas en caso de conflicto ${ }^{1}$. En segundo término, con los acuerdos de sumisión expresa se pueden elegir los tribunales de un determinado país por razones de neutralidad, especialización, agilidad procesal, o simplemente porque en ese país resulte más fácil obtener un adecuado asesoramiento jurídico ${ }^{2}$. Se añade, en tercer lugar, que los acuerdos de sumisión expresa pueden convertirse en un factor de reducción de costes para quien consiga concentrar todos los litigios que deriven de

\footnotetext{
Profesora Contratada Doctora (Acr. TU) en la Universidad de Sevilla (bcampuza@us.es).

1 JodlowsKi, J., "Les conventions relatives a la prorogation et a la dérogation a la compétence internationale en matière civile», RCADI, 1974, t. 143, pp. 475-588, esp. p. 503.

2 Kaufmann-Kohler, G., La clause d'élection de for dans les contrats internationaux, Basilea, Helbing \& Lichtenhahn, 1980, pp. 1-2.
} 
su actividad comercial ante los tribunales de un determinado país, sometiéndolos a un mismo Derecho $^{3}$.

2. La materialización de todas estas ventajas dependerá, no obstante, de que los Estados vinculados con la relación jurídica respeten los efectos de los acuerdos de sumisión expresa: el efecto de prórroga o prorrogatio fori, en cuya virtud debe conocer del litigio el tribunal elegido; y el efecto de derogación o derogatio fori, en cuya virtud debe abstenerse de conocer del litigio un tribunal distinto del elegido. Ello se producirá cuando el acuerdo de sumisión expresa sea eficaz y válido conforme al ordenamiento del tribunal elegido y conforme también al ordenamiento cuyo tribunal debe abstenerse de conocer, a pesar de gozar de competencia judicial internacional. La normativa reguladora de estos acuerdos puede ser compartida por un grupo de Estados, en cuyo caso se aplicaría una normativa uniforme y común ${ }^{4}$.

3. En este trabajo vamos a analizar la derogación de la competencia de nuestros tribunales cuando las partes se han sometido a los tribunales de un Estado extranjero con el que no nos vincula ningún instrumento internacional. Las disposiciones de la recientemente reformada Ley Orgánica 6/1985, de 1 de julio, del Poder Judicial («LOPJ») ${ }^{5}$ en relación con la derogatio fori van a constituir el objeto de nuestro estudio.

\section{LA ADMISIBILIDAD DE LA DEROGATIO FORI EN NUESTRO SISTEMA AUTÓNOMO}

\subsection{Antecedentes}

4. La admisibilidad de la derogatio fori ha pasado por diferentes fases en nuestra historia más reciente, que presentaremos brevemente conforme al siguiente esquema: una primera fase, previa a la aprobación de la LOPJ; una segunda fase, tras la aprobación de esta Ley, que introdujo una nueva regulación de la competencia judicial internacional; y una tercera fase, determinada por la reciente reforma de la LOPJ, mediante la Ley Orgánica 7/2015, de 21 de julio $^{6}$, a la que nos referiremos en el siguiente epígrafe.

5. En relación con la primera fase se impone aludir el trabajo que Enrique Pecourt García dedicó a esta cuestión. El autor, tras un amplio análisis de Derecho comparado en el que clasificaba diferentes ordenamientos en función del grado de admisibilidad que mostraban hacia la derogatio fori, llegaba a la conclusión de que nuestro país se encontraba entre los que no la

\footnotetext{
3 En este sentido es bien conocido el caso de la jurisprudencia estadounidense, Carnival Cruise Lines, Inc. v. Shute, véase Garcimartín Alférez, F. J., «Las cláusulas de elección de foro: fallos del mercado y abuso del derecho», REDI, 1998, núm. 2, pp. 93-119.

4 Garcimartín Alférez, F. J., Derecho internacional privado, 3. ${ }^{a}$ ed., Cizur Menor, Thomson Reuters, 2016, p. 177.

5 BOE núm. 157, de 2 de julio de 1985.

6 BOE núm. 174, de 22 de julio de 2015.
} 
admitían, a pesar de ciertos vaivenes jurisprudenciales, en base a argumentos vinculados con la idea de soberanía estatal y con la naturaleza pública e imperativa de las normas reguladoras de la competencia judicial internacional ${ }^{7}$.

6. La segunda fase vino marcada, como decíamos, por la aprobación de la LOPJ, que aunque no se refirió expresamente a la derogatio fori, sí introdujo una nueva regulación de la competencia judicial internacional, que permitía realizar una interpretación favorable a su admisibilidad. En defensa de esta interpretación, Julio D. González Campos y Miguel Amores Conradi se refirieron a los siguientes aspectos: el art. 22 LOPJ diferenciaba las competencias exclusivas de las restantes, que eran facultativas; la admisión de la sumisión expresa en favor de nuestros tribunales suponía que también debía admitirse en favor de tribunales extranjeros, sin que pudiera seguir defendiéndose el carácter indisponible de las normas de competencia judicial internacional; el reconocimiento de los efectos de un convenio arbitral debía acompañarse del reconocimiento también de los efectos de un acuerdo de sumisión a tribunales extranjeros, para no incurrir en una contradicción; los intereses de los particulares, en especial los de aquellos que operan en el comercio internacional, podían verse perjudicados de no admitirse los efectos de estos acuerdos de sumisión a tribunales extranjeros; y había que tener en cuenta además que nuestro sistema de eficacia extraterritorial de resoluciones daba por bueno el ejercicio de competencia de un tribunal extranjero basada en la sumisión expresa de las partes implicadas ${ }^{8}$. No obstante, otros autores como José Carlos Fernández Rozas y Sixto Sánchez Lorenzo, sin discutir la conveniencia de la admisibilidad de la derogatio fori, sí ponían el acento en que era necesario que esta figura se regulara en nuestro ordenamiento, dado que suponía privar al tribunal español de una competencia que le venía atribuida ex lege, lo cual afectaba al principio de legalidad, tan importante en el sector de la competencia judicial internacional ${ }^{9}$.

7. La jurisprudencia en esta segunda fase también tuvo vaivenes, aunque acabó consolidándose una línea interpretativa favorable a la admisibilidad de

\footnotetext{
7 «La voluntad de las partes y su posible virtualidad en la determinación de la competencia judicial internacional», REDI, 1964, núm. 1, pp. 60-80; núm. 3, pp. 370-405; núm. 4, pp. 528-560.

8 GonzÁlez CAmpos, J. D., «Lección X: Competencia judicial internacional», en PÉREZ Vera, E.

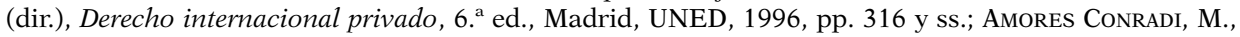
«La nueva estructura del sistema español de competencia judicial internacional en el orden civil: art. 22 LOPJ», REDI, 1989, núm. 1, pp. 113-156, esp. pp. 144 y ss. En sentido similar se expresaron también otros autores, véase Calvo Caravaca, A. L. y Carrascosa González, J., Derecho internacional privado, vol. I, 15. ${ }^{\text {a }}$ ed., Granada, Comares, 2014, p. 338; Rodríguez BENOT, A., Los acuerdos atributivos de competencia judicial internacional en derecho comunitario europeo, Madrid, Eurolex, 1994, pp. 90 y ss.; Virgós Soriano, M. y Garcimartín Alférez, F. J., Derecho procesal civil internacional. Litigación internacional, 2. ${ }^{\text {e }}$., Cizur Menor, Civitas, 2007, pp. 303-304. En relación con la vinculación que puede establecerse entre los intereses del comercio internacional y la derogatio fori resulta emblemático el caso de la jurisprudencia estadounidense M/S Bremen v. Zapata Off-Shore Company, en HaRTLEY, T. C., International Commercial Litigation. Text, Cases and Materials on Private International Law, Cambridge University Press, 2009, pp. 190 y ss.

9 Fernández Rozas, J. C., y SÁnchez Lorenzo, S., Derecho internacional privado, 8. a ed., Cizur Menor, Thomson Reuters, 2013, p. 110.
} 
la derogatio fori. En este sentido, la STS (Sala de lo Civil), de 30 de abril de 1990, siguió anclada en conceptos antiguos, refiriéndose a los vínculos existentes entre el ejercicio de la jurisdicción y la soberanía nacional como motivo para rechazar la derogatio for ${ }^{10}$. Le siguieron, en una línea negativa, la STS (Sala de lo Civil), de 18 de junio de $1990^{11}$, y la STS (Sala de lo Civil), de 20 de julio de 1992, donde se realizaron confusas consideraciones sobre la ley aplicable al fondo del litigio como condicionante de la admisibilidad de la derogatio fori ${ }^{12}$. En sentido favorable, la STS (Sala de lo Civil), de 19 de noviembre de $1990^{13}$, se refirió a que la libertad de las partes para someterse a un tribunal extranjero se veía avalada por el art. 22 LOPJ. Especialmente clara y contundente sería la STS (Sala de lo Civil), de 13 de octubre de $1993^{14}$, donde se afirmó que si el art. 22.2 de la LOPJ ofrecía la posibilidad de someterse a los tribunales españoles, sería absurdo y perturbador para el tráfico jurídico externo que no se admitiese la sumisión a tribunales extranjeros, cuando el litigio no se correspondiese con las materias objeto de competencia exclusiva. Después vendría la STS (Sala de lo Civil), de 10 de noviembre de $1993^{15}$, que mantendría la postura favorable a la admisibilidad de la derogatio fori, aunque acabaría rechazándola en este caso concreto con consideraciones relativas a que la invocaba el demandado domiciliado en España, lo cual suponía un abuso de Derecho que rayaba en el fraude procesal. Con carácter más reciente, y como muestra de la consolidación de la línea interpretativa favorable a la admisibilidad de la derogatio fori, cabe referirse a la STS (Sala de lo Civil, Sección $1 .^{\text {a }}$ ), de 31 de octubre de $2007^{16}$ y la STS (Sala de lo Civil, Sección $1 .^{\mathrm{a}}$ ) de 31 de mayo de $2012^{17}$.

8. A nivel de nuestras Audiencias Provinciales se ha seguido esta línea favorable a la admisibilidad, con base en los argumentos ya señalados. Como muestra cabe referirse a las Sentencias de la AP de Castellón de 26 de mayo de $1997^{18}$ y de la AP de Madrid (Sección 11. ${ }^{\mathrm{a}}$ ), de 30 de abril de $2004^{19}$, donde se aludió a la creciente internacionalización del tráfico mercantil, que se vería perturbado con posturas opuestas a la admisibilidad de la derogatio fori. La Sentencia de la AP de Madrid (Sección 14. ${ }^{\mathrm{a}}$ ), de 10 de julio de 2000, se refirió a la posibilidad de someterse a tribunales extranjeros con el límite de las competencias exclusivas ${ }^{20}$. Y junto a ellas, y también en línea con las consideraciones de nuestro Tribunal Supremo, las Sentencias de la AP Má-

10 REDI, 1990, núm. 2, con nota de AMOREs ConRadi, M., pp. 606-612.

11 REDI, 1991, núm. 1, con nota de González CAMPos, J. D., pp. 190-194.

12 REDI, 1993, núm. 2, con nota de Álvarez GonZÁLEZ, S., pp. 445-453.

13 REDI, 1991, núm. 1, pp. 194-195.

14 REDI, 1994, núm. 1, con nota de Álvarez Rubio, J. J., pp. 301-304.

15 REDI, 1994, núm. 1, con nota de Álvarez GonZÁlez, S., pp. 388-393.

16 REDI, 2007, núm. 2, con nota de AREnas García, R., pp. 758-760.

17 Consultada en CENDOJ, ECLI:ES:TS:2012:4025.

18 REDI, 1999, núm. 1, p. 170.

19 REDI, 2005, núm. 1, con nota de GARAU Sobrino, F., pp. 336-344.

${ }^{20} R E D I, 2001$, núms. 1 y 2, con nota de ARENAS GARCÍA, R., pp. 472-481. La posibilidad de someterse a tribunales extranjeros que acoge esta sentencia se vería posteriormente confirmada en la STS (Sala de lo Civil, Sección 1. ${ }^{\text {) }}$, de 31 de octubre de 2007, ya mencionada. 
laga (Sección 4..$^{\mathrm{a}}$ ), de 21 de mayo de $1994^{21}$, de la AP Badajoz (Sección 3. ${ }^{\mathrm{a}}$ ), de 23 de marzo de $2001^{22}$ y de la AP de Vizcaya (Sección 4. a), de 15 de marzo de $2002^{23}$, no descartaron la admisibilidad de la derogatio fori, aunque sí se refirieron a que cuando es el demandado domiciliado en nuestro país quien presenta la declinatoria por falta de jurisdicción, opera con manifiesto abuso de Derecho.

\subsection{La admisibilidad de la derogatio fori tras la Ley Orgánica 7/2015, de 21 de julio, por la que se modifica la Ley Orgánica 6/1985, de 1 de julio, del Poder Judicial}

9. La derogatio fori parece abordarse con cierta desconfianza. Tal como se ha señalado, los Estados son más reacios a regular la admisibilidad de la derogatio fori que la prorrogatio fori, y cuando la regulan suelen someterla a requisitos o límites específicos ${ }^{24}$.

10. Este sería el caso de nuestro país. La LOPJ se ocupó de la competencia judicial internacional en sus arts. 21 a 25 . En el art. 22.2 LOPJ reguló la sumisión expresa de las partes a nuestros tribunales en el orden civil, para nada dijo, como ya se ha visto, en relación con la posibilidad de someterse a un tribunal extranjero. Han tenido que pasar muchos años para que la LOPJ se reformara mediante la Ley Orgánica 7/2015, de 21 de julio, por la que se modifica la Ley Orgánica 6/1985, de 1 de julio, del Poder Judicial25, a la que le han llovido las críticas. Como con razón se ha señalado, se trata de una reforma que llega tarde; que extiende a varios preceptos la regulación de la competencia en el orden civil, lo cual resultaba innecesario debido a sus limitadas posibilidades de aplicación por la importante presencia de normas internacionales; y que presenta carencias técnicas, que en ocasiones llegan a manifestarse en expresiones sin sentido ${ }^{26}$. No obstante, el hecho de que se haya incorporado una regulación de la derogatio fori, aún con las deficiencias que tendremos ocasión de ir señalando, debe ser objeto de una valoración positiva.

11. Concretamente, se regula en el art. 22 ter, apartados 4 y 5 LOPJ, que no es el lugar más adecuado, por tratarse de un precepto que está dedicado al foro general del domicilio del demandado. En estos dos apartados, a los que nos referiremos en detalle más adelante, se establece que la competencia de

\footnotetext{
21 REDI, 1996, núm. 1, con nota de Esteban DE LA Rosa, F., pp. 287-294.

22 REDI, 2002, núm. 1, con nota de Esteban DE LA Rosa, F., pp. 365-371.

23 REDI, 2003, núm. 1, con nota de Álvarez GonzÁLEZ, S., pp. 375-384.

24 QueIrolo, I., Gli accordi sulla competenza giurisdizionale. Tra diritto comunitario e diritto interno, Padua, Cedam, 2000, p. 98.

${ }_{25}$ Sobre el proceso de reforma de la LOPJ, véase Herranz Ballesteros, M., «Anteproyecto de Ley orgánica del poder judicial: normas de competencia judicial internacional en el orden civil y social», REDI, 2014, núm. 2, pp. 339-345.

26 Calvo Caravaca, A. L. y Carrascosa González, J., Derecho internacional privado, vol. I, 16. a ed., Granada, Comares, 2016, pp. 337-338.
} 
nuestros tribunales podrá ser excluida en virtud de un acuerdo de elección de foro en favor de tribunales extranjeros, siempre que se trate de materias en las que estén permitidos los acuerdos de sumisión en favor de nuestros tribunales. Se añade, en el confuso art. 22 bis LOPJ, que no surtirán efectos los acuerdos que excluyan la competencia de los tribunales españoles exclusivamente competentes, conforme a lo establecido en el art. 22 LOPJ.

12. En definitiva, tras la reforma de la LOPJ se incorpora por fin a nuestro ordenamiento una disposición sobre la derogatio fori, que viene a completar, muchos años después, la regulación de los efectos de los acuerdos de sumisión expresa. Esta disposición, que pasamos a analizar, tiene como límite compartido con la prorrogatio fori que debe estar referida a una materia en la que esté permitido el acuerdo de las partes para fijar la competencia, y como límite específico que no debe afectar a materias de nuestra exclusiva competencia.

\section{LA APLICACIÓN SUBSIDIARIA DE LA LOPJ}

\subsection{El Reglamento (UE) núm. 1215/2012}

13. Son muchas las normas de origen internacional que vinculan a nuestro país y que permiten y regulan los acuerdos de sumisión expresa. Un papel fundamental le corresponde al Reglamento (UE) núm. 1215/2012, del Parlamento Europeo y del Consejo, de 12 de diciembre, relativo a la competencia judicial, el reconocimiento y la ejecución de resoluciones judiciales en materia civil y mercantil (refundición) ${ }^{27}$, que se aplica a los acuerdos celebrados en favor de los tribunales de un Estado miembro (art. 25). La prórroga de la competencia del tribunal del Estado miembro elegido y la derogación de la competencia de los tribunales de los demás Estados miembros viene determinada por esta normativa uniforme y común ${ }^{28}$. El efecto derogatorio depende del carácter exclusivo del acuerdo de sumisión expresa, que se presume salvo indicación en contrario (art. 25.1).

14. El Reglamento 1215/2012 no se pronuncia sobre los efectos de los acuerdos de sumisión expresa en favor de tribunales de terceros Estados, en supuestos en que los tribunales de los Estados miembros pudieran ser competentes con arreglo a alguna de las disposiciones del Reglamento (p. ej., en virtud del art. 4 relativo al foro del domicilio del demandado). La cuestión ya hace tiempo que se planteó en el marco del Convenio de Bruselas de 27

27 DO L núm. 351, de 20 de diciembre de 2012.

28 En relación con ello cabe referirse a la Sentencia del TJUE de 15 de noviembre de 2012, Gothaer Allgemeine Versicherung y otros, asunto C-456/11, ECLI:EU:C:2012:719, donde se afirmó que la resolución de un Estado miembro por la que declina su competencia en virtud de la existencia de una cláusula atributiva de competencia en favor de otros tribunales, debe ser reconocible en los demás Estados miembros. Esta conclusión no se vio afectada por el hecho de que en este caso la cláusula fuera a favor de los tribunales de Islandia y se hubiera tenido en cuenta el Convenio de Lugano, que en palabras del TJUE debe considerarse equivalente. 
de septiembre de $1968^{29}$, señalando el Informe Schlosser que la validez de tales acuerdos debía resolverse conforme al Derecho nacional de los Estados miembros ${ }^{30}$. Esta consideración se recogería posteriormente en la Sentencia del TJCE de 9 de noviembre de 2000, Coreck Maritime, asunto C-387/98 (p. 19) $)^{31}$.

15. No obstante, con posterioridad, dos decisiones del TJUE vinieron a causar cierta incertidumbre. Por una parte, la Sentencia del TJCE de 1 de marzo de 2005, Owusu, asunto C-281/02 ${ }^{32}$, donde se afirmó que el Convenio de Bruselas de 1968 se oponía a que un tribunal de un Estado miembro declinase la competencia que le confería el foro del domicilio del demandado, por considerar que era más adecuado que conociese el tribunal de un tercer Estado (p. 46). En este caso se trataba de la aplicación de la doctrina del forum non conveniens y no de reconocer los efectos de un acuerdo atributivo de competencia en favor de los tribunales de un tercer Estado, si bien el efecto final era el mismo: que el tribunal competente del Estado miembro declinase su competencia. Por otra parte, en el Dictamen del TJCE 1/03, de 7 de febrero de 2006, a propósito de la competencia para celebrar el nuevo Convenio de Lugano, de 30 de octubre de 2007, relativo a la competencia judicial y a la ejecución de resoluciones judiciales en materia civil y mercantil ${ }^{33}$, se afirmó que este Convenio contenía cláusulas idénticas a los arts. 22 y 23 del Reglamento $44 / 2001^{34}$, arts. 24 y 25 del Reglamento 1215/2012, que podían dar lugar a que se considerase competente al tribunal de un tercer Estado parte en el Convenio de Lugano a pesar de que el demandado estuviese domiciliado en un Estado miembro, en una circunstancia en que si no se aplicase este Convenio

29 DO C núm. 27, de 26 de enero de 1998 (versión consolidada).

30 Informe sobre el Convenio relativo a la adhesión del Reino de Dinamarca, de Irlanda y del Reino Unido de Gran Bretaña e Irlanda del Norte al Convenio relativo a la competencia judicial y a la ejecución de resoluciones judiciales en materia civil y mercantil, así como al Protocolo relativo a su interpretación por el Tribunal de Justicia de 9 de octubre de 1978, elaborado por el Profesor Dr. P. ScHLOSSER (DO C, núm. 189, de 28 de julio de 1990, párr. 176).

31 ECLI:EU:C:2000:606, nota de Jiménez Blanco, P., REDI, 2001, núms. 1 y 2, pp. 467-472. Átvarez GonzÁlez, S., en su nota a la Sentencia del TS (Sala 1. a), de 20 de julio de 1992, se refirió a la discusión doctrinal que existía en torno a si la remisión a los Derechos nacionales era a efectos de la admisibilidad y validez de la derogatio fori o solo de la validez, en un momento en que la cuestión tenía relevancia dadas las dudas que se suscitaban sobre la admisibilidad de la derogatio fori en nuestro sistema autónomo, op. cit., nota 10, p. 448. Posteriormente, en la Sentencia del TJUE de 19 de julio de 2012, Mahamdia, asunto C-154/11, ECLI:EU:C:2012:491, nota de MASEDA Rodríguez, J., en REDI, 2013, núm. 1, pp. 203-208, se señalaría en relación con una cláusula de sumisión expresa en favor de un tribunal de un tercer Estado inserta en un contrato de trabajo, que no podía perjudicar el objetivo de proteger al trabajador como parte contratante más débil a la que se le ofrece una pluralidad de foros (p. 64). El TJUE estableció restricciones para proteger a una parte débil, adentrándose, en relación con esta materia donde la normativa europea está inspirada en un principio de protección, en cuestiones vinculadas con la admisibilidad. En sentido similar se había pronunciado con anterioridad nuestro Tribunal Supremo (Sala de lo Social) en su Sentencia de 12 de junio de 2003, REDI, 2003, núm. 2, con nota de EsPinIElla MENÉNDEZ, A., pp. 924-931.

32 ECLI:EU:C:2005:120.

33 DO L núm. 339, de 21 de diciembre de 2007.

34 Reglamento (CE) núm. 44/2001, del Consejo, de 22 de diciembre de 2000, relativo a la competencia judicial, el reconocimiento y la ejecución de resoluciones judiciales en materia civil y mercantil, DO L núm. 12, de 16 de enero de 2001. 
de Lugano sería competente el tribunal de un Estado miembro (p. 153) ${ }^{35}$. En definitiva, y según la doctrina, parecía sugerirse con esta afirmación que en defecto de convenio no había por qué respetar las competencias exclusivas de terceros Estados o los acuerdos de sumisión expresa en favor de tribunales de terceros Estados ${ }^{36}$.

16. Durante el proceso de reforma del Reglamento 44/2001 se abogó por que se evitara esta situación de incertidumbre, siendo especialmente activo en este sentido el Grupo Europeo de Derecho Internacional Privado ${ }^{37}$. No obstante, el hecho de que no se hiciera, y de que sí se incorporara en el Reglamento 1215/2012 una solución para los supuestos de litispendencia y conexidad con terceros Estados, que podrá aplicarse, entre otras circunstancias, cuando el órgano del tercer Estado tenga competencia exclusiva (cdo. 24), ha generado ciertas dudas en torno a si el respeto a las competencias exclusivas de terceros Estados o a los acuerdos de sumisión expresa en favor de tribunales de terceros Estados se limitaría a estas reglas, dependientes de que el proceso se hubiera iniciado en el tercer Estado con anterioridad ${ }^{38}$. A nosotros nos parece más correcta y prudente la postura de quienes señalan que el Reglamento 1215/2012 no ha resuelto finalmente esta cuestión ${ }^{39}$, considerando los limitados efectos que se quisieron que esta norma tuviera en las relaciones conectadas con terceros Estados ${ }^{40}$. Ello supondría, en definitiva, que la validez de los acuerdos de sumisión expresa en favor de tribunales de terceros Estados seguiría dependiendo de las normas nacionales de competencia judicial internacional, en nuestro país de la LOPJ.

\subsection{Otros instrumentos internacionales}

17. Nuestro país se encuentra vinculado por otros instrumentos internacionales que también regulan los acuerdos de sumisión expresa. En el plano multilateral hay que referirse al Convenio de Lugano, que se aplica en los

35 ECLI:EU:C:2006:81.

36 FRANCQ, S., «La refonte du Règlement Bruxelles: champ d'application et compétence», Revue de Droit Commercial Belge, 2013, núm. 5, pp. 307-333, esp. p. 313.

37 Este Grupo llegó incluso a presentar un borrador de los artículos que debían incorporarse al Reglamento para cubrir estas situaciones. Véase Consolidated version of a proposal to amend Regulation 44/2001 in order to apply it to external situations (Bergen, 21 de septiembre de 2008, Padua, 20 de septiembre de 2009, Copenhagen, 19 de septiembre de 2010), http://www.gedip-egpil.eu (consultada el 19 de octubre de 2017).

38 Sobre el debate existente a este respecto véase CAMPUZANO DíAZ, B., «Las normas de competencia judicial internacional del Reglamento 1215/2012 y los demandados domiciliados fuera de la UE: análisis de la reforma», REEI, 2014, núm. 28, pp. 1-35, esp. pp. 20 y ss.

39 NuYTs, A., "La refonte du règlement Bruxelles I», Revue critique de droit international privé, 2013, pp. 1-64, esp. p. 9; France, S., op. cit., nota 30, pp. 319-320.

${ }^{40}$ Cabe señalar que en la Sentencia del TJUE de 17 de marzo de 2016, Taser International Inc., asunto C175/15, ECLI:EU:C:2016:176, aunque se trataba de un supuesto referido aún al Reglamento 44/2001, no se descartaron los efectos de una cláusula de sumisión expresa en favor de los tribunales de un tercer Estado con el argumento de que ya se había iniciado un proceso ante los tribunales de un Estado miembro, sino en base a que la parte demandada se había sometido a estos tribunales y la sumisión tácita prevalece sobre la expresa (p. 25). 
Estados miembros de la Unión Europea, Suiza, Noruega e Islandia. Como es bien sabido, se trata de un convenio muy similar en su contenido al Reglamento 1215/2012, que se ocupa de los acuerdos de sumisión en su art. 23. Igualmente, el Convenio de La Haya de 30 de junio de 2005 sobre acuerdos de elección de foro ${ }^{41}$, que regula los efectos prorrogatorios y derogatorios que derivan de estos acuerdos en sus arts. 5 y 6 respectivamente. Este Convenio se aplica únicamente a los acuerdos de elección de foro con carácter exclusivo, previendo también una presunción en favor de su exclusividad (arts. 1.1 y 3). La UE se ha adherido a este Convenio, que por el momento está teniendo una aceptación muy limitada más allá del ámbito europeo — solo se encuentra vigente en México y Singapur-. En el plano bilateral debemos referirnos al Tratado entre España y El Salvador sobre competencia judicial, reconocimiento y ejecución de sentencias en materia civil y mercantil, hecho en Madrid el 7 de noviembre de $2000^{42}$, que también se refiere a la sumisión expresa en su art. $5.2^{43}$.

18. Se añade que nuestro país se encuentra vinculado por una red de Convenios referidos a materias específicas, que en algunos casos incorporan normas de competencia judicial internacional que permiten a las partes elegir el tribunal competente, fundamentalmente en el sector del transporte internacional. El efecto derogatorio de la competencia de nuestros tribunales que pudiera derivar de estos convenios dependerá de cómo configuren el acuerdo de sumisión expresa, particularmente de si lo hacen con carácter exclusivo de modo que no sea posible acudir a otro tipo de foros ${ }^{44}$.

19. Hasta ahora todos los Instrumentos mencionados se refieren a cuestiones de derecho patrimonial. Su ámbito material coincide con el cubierto por el Reglamento $1215 / 2012$, lo cual plantea a veces complicados problemas de delimitación, sobre los que no vamos a entrar aquí. Pero junto a ellos, y por obra de la Unión Europea, hemos de señalar que los acuerdos de elección de foro también se han adentrado en importantes sectores del Derecho de familia y sucesiones, ofreciéndose en diversos Reglamentos un marco normativo uniforme en relación con su eficacia y validez, que prima sobre nuestra normativa interna. En este sentido hay que referirse al Reglamento (CE) núm. 4/2009 en materia de alimentos ${ }^{45}$, que en su art. 4 consagra, con ciertas limitaciones en función de los sujetos afectados, los acuerdos de elección de

41 DO L núm. 133, de 29 de mayo de 2009.

42 BOE núm. 256, de 25 de octubre de 2001.

43 Aunque en este precepto no se establece expresamente una presunción en favor del carácter exclusivo del acuerdo, así parece desprenderse de su tenor literal y de la distribución de competencia que hace en las relaciones bilaterales entre España y El Salvador.

44 Para un análisis muy completo de estos convenios internacionales referidos a materias específicas, con referencia a las circunstancias en que permiten los acuerdos de sumisión expresa así como a los aspectos de estos acuerdos que regulan, véase GARAU SoBRINO, F., Los acuerdos internacionales de elección de foro, Madrid, Colex, 2008, pp. 46 y ss.

45 Reglamento (CE) núm. 4/2009, del Consejo, de 18 de diciembre de 2008, relativo a la competencia, la ley aplicable, el reconocimiento y la ejecución de las resoluciones y la cooperación en materia de obligaciones de alimentos, DO L núm. 7, de 10 de enero de 2009. 
foro; al Reglamento (UE) núm. 650/2012 en materia sucesoria ${ }^{46}$, que presenta como particularidad que la elección de foro aparece vinculada a la previa elección de la ley aplicable realizada por el causante (art. 5); y a los Reglamentos (UE) núms. 2016/1103 y 2016/1104 relativos a los regímenes económico-matrimoniales y efectos patrimoniales de las parejas de hecho registradas ${ }^{47}$, que también vinculan la elección del tribunal competente con la ley aplicable o el lugar de celebración del matrimonio o conforme a cuya ley se haya creado la unión registrada, respectivamente (art. 7 de ambos Reglamentos) ${ }^{48}$. En todos los Reglamentos mencionados se contempla el carácter exclusivo del acuerdo.

\section{EL REGIMEN DE LA DEROGATIO FORI EN LA LOPJ}

\subsection{Naturaleza de los foros derogables y materias en relación con las que se admite la derogatio fori}

20. La naturaleza de los foros derogables y especialmente las materias en relación con las que puede admitirse la derogatio fori no tienen una respuesta clara, debido a la deficiente redacción que presenta la LOPJ tras su reforma.

21. Para determinar la naturaleza de los foros derogables hay que referirse al art. 22 ter.4 LOPJ, que dispone lo siguiente: «No obstante, la competencia establecida conforme a lo dispuesto en el apartado 1 de este artículo podrá ser excluida mediante un acuerdo de elección de foro a favor de un Tribunal extranjero». Como vemos, se realiza una remisión al art. 22 ter. 1 LOPJ, que se refiere a «materias distintas a las contempladas en los artículos 22, 22 sexies y 22 septies», estableciendo a continuación que «si no mediare sumisión a los Tribunales españoles de conformidad con el artículo 22 bis, estos resultarán competentes cuando el demandado tenga su domicilio en España o cuando así venga determinado por cualquiera de los foros establecidos en los artículos 22 quáter y 22 quinquies».

22. Pues bien, de esa remisión al art. 22 ter.1 LOPJ, cuyo tenor literal acabamos de reflejar, entendemos que pueden extraerse dos conclusiones de

46 Reglamento (UE) núm. 650/2012, del Parlamento Europeo y del Consejo, de 4 de julio, relativo a la competencia, la ley aplicable, el reconocimiento y la ejecución de las resoluciones, a la aceptación y la ejecución de los documentos públicos en materia de sucesiones mortis causa y a la creación de un certificado sucesorio europeo, DO L núm. 201, de 27 de julio de 2012.

47 Reglamento (UE) 2016/1103, del Consejo, de 24 de junio, por el que se establece una cooperación reforzada en el ámbito de la competencia, la ley aplicable, el reconocimiento y la ejecución de resoluciones en materia de regímenes económicos matrimoniales y Reglamento (UE) 2016/1104, del Consejo, de 24 de junio, por el que se establece una cooperación reforzada en el ámbito de la competencia, la ley aplicable, el reconocimiento y la ejecución de resoluciones en materia de efectos patrimoniales de las uniones registradas, $D O$ L núm. 183, de 8 de julio de 2016.

48 Se añadiría el art. 12 del Reglamento 2201/2003, del Consejo, de 27 de noviembre, relativo a la competencia, el reconocimiento y la ejecución de resoluciones judiciales en materia matrimonial y de responsabilidad parental, por el que se deroga el Reglamento (CE) núm. 1347/2000, DO L núm. 338, de 23 de diciembre de 2003, que prevé la prórroga de la competencia en materia de responsabilidad parental en unas circunstancias muy concretas. El Convenio de La Haya de 19 de octubre de 1996 recoge en su art. 10 una disposición similar. 
cara a determinar la naturaleza de los foros derogables. La primera conclusión es que la derogatio fori se permite en materias distintas de las contempladas en los arts. 22, 22 sexies y 22 septies, que se refieren a los foros de competencia exclusiva, las medidas provisionales y de aseguramiento y la materia concursal, respectivamente.

23. La exclusión de la derogatio fori de las materias reguladas con foros de naturaleza exclusiva se confirma además en el art. 22 bis.1 LOPJ, conforme a la interpretación que le da sentido a este confuso precepto, al que después nos referiremos. Se trata de una exclusión que está en línea con lo que ya venía manteniéndose unánimemente a nivel doctrinal ${ }^{49}$ y en nuestra jurisprudencia ${ }^{50}$. Se añade que las materias reguladas en el art. 22 LOPJ coinciden con las reguladas en el art. 24 del Reglamento 1215/2012, que será el precepto realmente aplicable para fundamentar la competencia de nuestros órganos jurisdiccionales, y que por su carácter imperativo no permite el juego de la voluntad de las partes implicadas.

24. La exclusión de las medidas provisionales o de aseguramiento resulta lógica desde una perspectiva práctica, pues no tendría sentido que las partes acordaran la competencia de un tribunal extranjero para adoptar este tipo de medidas ${ }^{51}$. La materia concursal, donde se debe dar respuesta con carácter colectivo a los intereses de un número indeterminado de acreedores, no resulta apropiada para los acuerdos de sumisión. La normativa específica existente al respecto, a la que se remite desde el art. 22 septies LOPJ - Reglamento (UE) $2015 / 848^{52}$ y Ley 22/2003, de 9 de julio, Concursal ${ }^{53}$-, así lo demuestra.

25. La segunda conclusión a la que nos referíamos es que la derogatio fori sí se permitirá en relación con los foros de competencia comprendidos en el art. 22 ter.1 LOPJ, que son el foro de la sumisión, el foro general del domicilio del demandado y los foros especiales de los arts. 22 quáter y 22 quinquies. Como en este caso se trata de determinar la operatividad del acuerdo de sumisión expresa en favor de tribunales extranjeros debemos descartar la referencia a la sumisión a los tribunales españoles, quedándonos que la derogatio fori puede operar en aquellos supuestos en que nuestros tribunales resulten competentes en base al foro general del domicilio del demandado o en base a los foros especiales ${ }^{54}$.

\footnotetext{
49 Amores Conradi, M., op. cit., nota 8, p. 147; Calvo Caravaca, A. L. y Carrascosa González, J., op. cit., nota 8, p. 339; GARAU Sobrino, F., op. cit., nota 44, p. 186; RodríGUEz BENOT, A., op. cit., nota 8, p. 97; Virgós Soriano, M. y Garcimartín Alférez, F. J., op. cit., nota 8, pp. 303-304.

50 Anteriormente ya tuvimos oportunidad de referirnos a la claridad con la que se pronunció en favor de la derogatio fori la Sentencia del TS (Sala $1 .^{\mathrm{a}}$ ), de 13 de octubre de 1993, haciendo la salvedad de las materias objeto de competencia exclusiva (véase párr. 7).

51 Garau Sobrino, F., op. cit., nota 44, pp. 187-188.

52 Reglamento (UE) 2015/848 del Parlamento Europeo y del Consejo, de 20 de mayo de 2015, sobre procedimientos de insolvencia, DO L núm. 141, de 5 de junio de 2015.

53 BOE núm. 164, de 10 de julio de 2003.

54 En este sentido Esplugues Mota, C., Iglesias Buhigues, J. L. y Palao Moreno, G., Derecho internacional privado, 11. a ed., Valencia, Tirant lo Blanch, 2017, p. 165; Fernández Rozas, J. C. y SÁnCHEZ
} 
26. Una vez determinada la naturaleza de los foros derogables, la cuestión que toca plantearse a continuación es si en relación con todas las materias cubiertas por estos foros puede ser operativa la derogatio fori. Al respecto, el art. 22 ter.5 LOPJ dispone que «no tendrá efecto la exclusión de la competencia de los tribunales españoles en aquellas materias en que no cabe sumisión a ellos». En definitiva, se impone consultar cuáles son las materias respecto de las cuales cabe sumisión expresa a los tribunales españoles y, consecuentemente, a tribunales extranjeros.

27. Tenemos que ir para ello al art. 22 bis. 1 de la LOPJ, cuyo tenor literal carece de sentido. Dice este precepto: «En aquellas materias en que una norma expresamente lo permita, los Tribunales españoles serán competentes cuando las partes, con independencia de su domicilio, se hayan sometido expresa o tácitamente a ellos. No surtirán efectos los acuerdos que atribuyan competencia a los tribunales españoles ni las estipulaciones similares incluidas en un contrato si son contrarios a lo establecido en los artículos 22 quatér, 22 quinquies, 22 sexies y 22 septies, o si excluyen la competencia de los órganos jurisdiccionales españoles exclusivamente competentes conforme a lo establecido en el artículo 22, en cuyo caso se estará a lo establecido en dichos preceptos».

28. Este precepto ya ha suscitado elocuentes comentarios. Por una parte, llama la atención la referencia que se hace a que nuestros tribunales serán competentes en aquellas materias en que una norma expresamente lo permita. Tal como se ha señalado, si el objetivo de la LOPJ es fijar la competencia de nuestros tribunales: ¿qué sentido tiene referirse a una norma para que lo permita? ${ }^{55}$. Además, si con esa referencia se quiere aludir a una norma extraña a la propia LOPJ, como no existe, una interpretación literal del art. 22 bis LOPJ llevaría a la absurda conclusión de que la sumisión en favor de nuestros tribunales es imposible ${ }^{56}$. Por otra parte, el art. 22 bis.1 LOPJ prosigue señalando, como hemos visto, que no surtirán efectos los acuerdos que atribuyan competencia a los tribunales españoles si son contrarios a lo establecido en los arts. 22 quatér, 22 quinquies, 22 sexies y 22 septies, o si excluyen la competencia de los órganos jurisdiccionales españoles exclusivamente competentes conforme a lo establecido en el art. 22. Es evidente que la norma incurre en un sinsentido, pues no puede haber una sumisión a los tribunales españoles

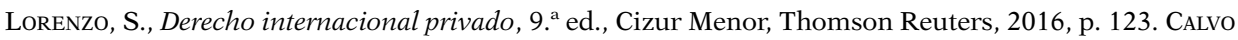
CARavaca, A. L. y Carrascosa González, J., señalan que como la derogatio fori se regula en el art. 22 ter LOPJ relativo al foro del domicilio del demandado, podría entenderse que solo este foro es el derogable; aunque concluyen señalando que la lógica y el buen sentido, así como el hecho de que el Reglamento $1215 / 2012$ sea la norma modelo, inclinan a pensar que también pueden derogarse los foros especiales, op. cit., nota 26 , p. 386.

55 Garcimartín Alférez, F. J., «La competencia judicial internacional en la reforma de la Ley Orgánica del Poder Judicial», Diario La Ley, núm. 8614, de 28 de septiembre de 2015, pp. 1-11, esp. p. 4.

56 Calvo Caravaca, A. L. y Carrascosa González, J., op. cit., nota 26, p. 358; Cordero Álvarez, C. I., «La autonomía jurisdiccional en el sistema autónomo español tras la reforma de la LOPJ», en OTERO GARCía CASTRILlón, C. (dir.), Justicia civil en la Unión Europea. Evaluación de la experiencia española y perspectivas de futuro, Madrid, Dykinson, 2017, pp. 97-116, esp. p. 99. 
que sea contraria a unas normas que tienen por objeto fijar la competencia de estos mismos tribunales.

29. En definitiva, el tenor literal del art. 22 bis.1 LOPJ resulta extremadamente confuso, lo cual tiene escasa incidencia desde el punto de vista de la prorrogatio fori por la preferencia aplicativa de numerosos instrumentos internacionales, y en particular del Reglamento 1215/2012, pero no así desde el punto de vista de la derogatio fori. Interesa reflexionar sobre el sentido querido de la norma, o al menos intentarlo, para determinar el ámbito material de admisibilidad de la derogatio fori en nuestra LOPJ ${ }^{57}$.

30. Si consideramos el contexto de la norma objeto de análisis, que es con la que se inicia el art. 22 bis LOPJ relativo a la sumisión a nuestros tribunales, cabe entender que a lo que pretendía referirse el legislador es a las materias en relación con las cuales pueden someterse las partes a nuestros tribunales. Se ha señalado que la dicción correcta del precepto, conforme a la intención querida del legislador, hubiera sido «en aquellas materias en las que no se excluya la sumisión o se condicione su ejercicio», "no surtirán efectos los acuerdos atributivos de competencia que no se ajusten a las condiciones establecidas en los arts. 22 quáter y 22 quinquies LOPJ ${ }^{58}$. Se excluye de consideración la referencia que también se hace en el art. 22 bis LOPJ a los arts. 22 sexies y 22 septies LOPJ referidos a las medidas provisionales o de aseguramiento y a la materia concursal, por las razones anteriormente apuntadas.

31. Pues bien, dicha propuesta interpretativa llevaría a un resultado lógico en relación con el art. 22 quinquies LOPJ. Este precepto se refiere a los foros especiales en materia patrimonial, fundamentalmente obligaciones contractuales y extracontractuales, haciendo referencia expresamente en su encabezado a que se aplicarán en defecto de sumisión expresa o tácita. Resulta por tanto claro que en relación con las materias previstas en el art. 22 quinquies LOPJ se admite la sumisión y no se excluye su ejercicio. En relación con algunas de las materias contempladas - los contratos de consumo y seguros- se establecen además condiciones especiales, inspiradas en el Reglamento 1215/2012 ${ }^{59}$. La conclusión, en el ámbito que a nosotros interesa,

57 Garcimartín AlfÉrez, F. J., se muestra sin embargo partidario de una solución más drástica, al señalar que puede imaginarse lo que realmente quiso decir el legislador y a partir de ahí intentar «reconstruir» todo el precepto, pero que lo más oportuno sería simplemente hacer una interpretatio abrogans, por absurdo, de este apartado, op. cit., nota 55, p. 4.

58 EsPinar Vicente, J. M. y PARedes Pérez, J. I., «Análisis y valoración crítica de la regulación de la sumisión a la jurisdicción española antes y después de la reforma de la Ley Orgánica del Poder Judicial (LO 7/1985)», AEDIPr, t. XVI, 2016, pp. 199-247, esp. pp. 232-233; EsPINAR VICENTE, J. M., «Los riesgos de la incorrecta adaptación de las normas de la Unión Europea. La sumisión de las partes a la jurisdicción española tras la reforma de la Ley Orgánica del Poder Judicial de 2015», La Ley, Unión Europea, 30 de noviembre de 2015, núm. 31, pp. 1-6, esp. p. 3.

59 Como muestra de la defectuosa técnica legislativa de la LOPJ, las limitaciones en relación con los contratos de seguro y consumo se reiteran, con algún matiz diferenciador, tanto en el art. 22 bis.1.II como en el párrafo final del art. 22 quinquies LOPJ. Sobre las limitaciones en relación con las cláusulas de sumisión expresa insertas en las condiciones generales referidas a contratos de consumo, véase Feliu Álvarez de Sotomayor, S., «Nulidad de las cláusulas de jurisdicción y ley aplicable a la luz de la 
sería que en relación con las materias contempladas en el art. 22 quinquies LOPJ se admitiría la derogatio fori, con la limitación particular en aquellos contratos en los que existe una parte débil como, por otra parte, ya venía defendiendo la doctrina antes de la reforma de la LOPJ ${ }^{60}$.

32. Interesa señalar que el contrato de trabajo no se contempla por tratarse de una materia regulada en el art. 25 LOPJ relativo al orden social, a pesar de que en el marco del Reglamento 1215/2012 se regula de forma muy similar a los contratos de consumo y seguros. Anteriormente ya tuvimos oportunidad de referirnos a la Sentencia del TJUE de 19 de julio de 2012, Mahamdia, asunto C$154 / 11^{61}$, donde no se descartó la eficacia de una cláusula de sumisión expresa en favor de los tribunales de un tercer Estado inserta en un contrato de trabajo, siempre que no privara al trabajador, como parte más débil, de la posibilidad de acudir a otros tribunales que fueran competentes con arreglo al Reglamento. EL TJUE realizó una interpretación tuitiva de los intereses del trabajador, en línea similar a lo que establece nuestra LOPJ en relación con los contratos de consumo y seguros, que puede servir de modelo a nuestros tribunales.

33. Por otra parte, más difícil resulta llegar a una conclusión clara con la propuesta interpretativa anteriormente señalada en relación con el art. 22 quáter LOPJ, donde se regulan los foros especiales en materia de persona, familia y sucesiones. Para empezar, este precepto, a diferencia del art. 22 quinquies LOPJ, no hace referencia expresa en su encabezado a los acuerdos de sumisión expresa o tácita. Aunque alude a que es aplicable en defecto de los criterios anteriores, entre los que se encontraría el art. 22 bis LOPJ relativo a la sumisión, lo cierto es que la diferencia de redacción que presenta con el art. 22 quinquies LOPJ da pie a divergencias interpretativas ${ }^{62}$. Se añade que de acogerse una interpretación favorable a que no se excluye la operatividad de la sumisión, se observa que solo se establece en el art. 22 quáter LOPJ un condicionante en relación con la elección de foro en materia sucesoria, sin que tenga sentido, considerando las materias que se regulan, entender su admisión generalizada en relación con las demás. La problemática se trata de solventar con la referencia a un condicionante implícito basado en un criterio de proximidad, siempre que se trate de un procedimiento de jurisdicción contenciosa en el que haya partes que puedan disponer libremente de sus derechos para llegar a un acuerdo ${ }^{63}$.

\footnotetext{
Ley 3/2014 por la que se modifica el texto refundido de la ley general para la defensa de consumidores y usuarios», REEI, 2015, núm. 29, pp. 1-36.

60 Amores Conradi, M., op. cit., nota 8, p. 147; Calvo Caravaca, A. L. y Carrascosa González, J., op. cit., nota 8, p. 339; Virgós Soriano, M. y Garcimartín Alférez, F. J., op. cit., nota 8, pp. 303-304.

61 Véase nota 31.

62 Espinar Vicente, J. M. y Paredes Pérez, J. I., no descartan los acuerdos de sumisión en relación con las materias comprendidas en el art. 22 quater LOPJ, op. cit., nota 58, pp. 235-236. Pero FERNÁNDEZ RozAS, J. C. y SÁNCHEZ LoRENZO, S., se muestran más partidarios de una interpretación que atienda al tenor literal del art. 22 quáter, que no se refieren expresamente a la sumisión con la salvedad de la materia sucesoria, aun reconociendo que se trataría de una solución que carecería de justificación debido al tenor de los instrumentos europeos, op. cit., nota 54, p. 114.

63 Espinar Vicente, J. M. y Paredes Pérez, J. I., op. cit., nota 58, pp. 235-236; Calvo Caravaca, A. L. y CARrascosa GonzÁlez, J., señalan concretamente que en base a estos requisitos quedarían fuera del
} 
34. Con independencia de estos posicionamientos a nivel doctrinal, sí tenemos al menos la certeza de que los acuerdos de sumisión expresa se permiten en diversos Reglamentos de la UE vinculados al Derecho de familia y sucesiones, con ciertas limitaciones basadas en un criterio de proximidad y particulares exigencias de carácter formal - Reglamentos 2201/2003, 4/2009, 650/2012, 2016/1103, 2016/1104-, que en algunos casos llegan a desplazar por completo a nuestra LOPJ. La referencia que se hace en el art. 22 ter.5 LOPJ a que no tendrá efecto la exclusión de la competencia de los tribunales españoles en aquellas materias en que no cabe sumisión a ellos, debería llevarnos, dada la deficiente redacción de la LOPJ, a tomar como guía lo dispuesto en los Reglamentos europeos ${ }^{64}$. En las materias previstas en los Reglamentos mencionados queda claro que se admite la sumisión a los tribunales españoles, y si ése es el criterio a seguir para determinar el ámbito de admisibilidad de la derogatio fori, habría que actuar en consecuencia ${ }^{65}$.

\footnotetext{
ámbito de la sumisión los litigios cuyo objeto versa sobre el estado jurídico de los menores, los que se refieren a cuestiones vinculadas a la identidad y capacidad de las personas, como son los procesos de incapacitación y filiación, y los procesos en los que estén presentes intereses públicos o estatales o relativos al funcionamiento de los servicios públicos, op. cit., nota 26, p. 359. Para un análisis del impacto que puede tener el carácter inquisitivo o dispositivo del proceso o el carácter de jurisdicción contenciosa o voluntaria del proceso sobre el ejercicio de la autonomía de la voluntad, véase JiMÉNEZ BLANCO, P., «Alcance de la autonomía de la voluntad en los procesos sobre persona y familia», en GuZmán Zapater, M. y Esplugues Mota, C. (dirs.), Herranz Ballesteros, M. y Vargas Gómez-Urrutia, M. (coords.), Persona y familia en el nuevo modelo español de Derecho internacional privado, Valencia, Tirant lo Blanch, 2017, pp. 51-74, esp. pp. 56 y ss.

64 El Reglamento 2201/2003 no contempla los acuerdos de elección de foro en relación con los supuestos de divorcio y separación judicial y la propuesta de reforma que se está tramitando tampoco, véase CAmpuzano DíAZ, B., «La propuesta de reforma del Reglamento 2201/2003: ¿se introducen mejoras en la regulación de la competencia judicial internacional?», en GUZMÁN ZAPATER, M. y ESPLUGUES Mota, C. (dirs.), Herranz Ballesteros, M. y Vargas Gómez-Urrutia, M. (coords.), Persona y familia en el nuevo modelo español de Derecho internacional privado, Valencia, Tirant lo Blanch, 2017, pp. 91-102. Como ello obedece a un criterio de política legislativa consistente en que la adopción de esta reforma no se vea afectada por el principio de unanimidad y no a que se consideren inadecuados los acuerdos de elección de foro en relación con esta materia, pensamos que el divorcio y la separación judicial podrían quedar incluidos en el ámbito material de admisibilidad de la derogatio fori. De hecho, contamos con antecedentes jurisprudenciales en nuestro país en los que se han aceptado los acuerdos de sumisión en relación con esta materia, véase Calvo CARAVACA, A. L. y CARRascosa GonzÁlez, J., op. cit., nota 26, p. 359.

65 Se ha planteado si en relación con estos Reglamentos debería seguirse el mismo criterio que hemos visto a propósito del Reglamento 1215/2012, donde se mantiene que la derogatio fori depende del Derecho nacional dado que el Reglamento no se ocupa de esta cuestión —recuérdese el Informe Schlosser y la Sentencia del TJCE de 9 de noviembre de 2000, Coreck Maritime, asunto C-387/98- Una postura diferente en relación con estos Reglamentos se basaría en el completo desplazamiento que algunos de ellos hacen de las soluciones contenidas en la LOPJ, de forma que si el Reglamento en cuestión no se ocupa de los acuerdos de sumisión en favor de los tribunales de un tercer Estado habría que descartar su eficacia. No obstante, estamos de acuerdo con JiméNEZ Blanco, P. cuando afirma que se trataría de un argumento de carácter formal y que resultaría cuestionable que esta normativa europea tuviera tal vocación de universalidad como para privar de toda eficacia derogatoria a un acuerdo de sumisión en favor de los tribunales de un tercer Estado, op. cit., nota 63, p. 64 .
} 


\subsection{El acuerdo tiene que celebrarse con ocasión de una determinada relación jurídica en favor de un tribunal extranjero}

35. Para que se plantee la derogatio fori las partes deben haberse sometido expresamente a los tribunales de un Estado extranjero. Tras la reforma de la LOPJ, el art. 22 bis. 2 ofrece una definición de qué debe entenderse por acuerdo de sumisión expresa a favor de los tribunales españoles: «Aquel pacto por el cual las partes deciden atribuir a los Tribunales españoles el conocimiento de ciertas o todas las controversias que hayan surgido o puedan surgir entre ellas respecto de una determinada relación jurídica, contractual o no contractual» ${ }^{6}$. Esta misma definición habrá de servirnos para apreciar, desde nuestra perspectiva de análisis, cuándo se han sometido a un tribunal extranjero.

36. Como cabe observar se requiere un pacto, esto es, que las partes se hayan puesto de acuerdo a través de la expresión de su consentimiento. Como la existencia del consentimiento se ha venido vinculando con el cumplimiento de los requisitos formales, nos referiremos a esta cuestión en el siguiente epígrafe. En segundo término, ese pacto debe ser para atribuir competencia a los tribunales españoles, que en nuestro caso sería a tribunales extranjeros. Siguiendo las pautas interpretativas que nos ofrece el Reglamento 1215/2012, por la evidente influencia que ha tenido en nuestra LOPJ, el pacto podrá realizarse en favor de los tribunales de un Estado extranjero en general o de un tribunal específico de un Estado extranjero, pudiendo bastar también una circunstancia objetiva que permita determinar con claridad el tribunal al que las partes han querido someterse. En tercer lugar, el pacto o acuerdo de sumisión expresa debe estar referido a una determinada relación jurídica, que es una cuestión diferente del alcance que se quiera dar a este acuerdo. Como dice el propio art. 22 bis. 2 LOPJ, el acuerdo puede estar referido al conocimiento de ciertas o todas las controversias que hayan surgido o puedan surgir entre las partes respecto de una determinada relación jurídica, contractual o no contractual ${ }^{67}$. En cuarto término, aunque en la definición del art. 22 bis. 2 LOPJ no se haga una referencia a la presunción en favor del carácter exclusivo del acuerdo, pues desde una perspectiva unilateral no tendría sentido ir más allá de aludir a la competencia

66 La incorporación de esta definición debe valorarse positivamente, pues con anterioridad se acudía a los requisitos previstos en nuestras normas internas de competencia territorial, que no resultaban adecuados, véase Rodríguez BENOT, A., «España en el espacio judicial europeo: ¿primeros tropiezos jurisprudenciales?», REDI, 1994, núm. 2, pp. 587-627, esp. pp. 598-599.

67 Como se señaló en la Sentencia del TJCE de 10 de marzo de 1992, Powell Duffryn, asunto C-214/89, ECLI:EU:C:1992:115, con este requisito se trata de evitar que una parte resulte sorprendida por la atribución a un foro determinado de todas las controversias que puedan darse en las relaciones que mantiene con la otra parte y que puedan derivar de relaciones distintas de aquella con motivo de la cual se pactó el acuerdo atributivo de competencia (p. 31). En la Sentencia del TJUE de 21 de mayo de 2015, CDC Hydrogen Peroxide, asunto C-352/13 (ECLI:EU:C:2015:335) se ha vuelto a aludir a esta cuestión, incorporando reflexiones sobre si la cláusula incorporada en un contrato podría extenderse a cuestiones de responsabilidad delictual (pp. 68-69). 
de los tribunales españoles, entendemos que cabe deducirla del art. 22 ter.4 LOPJ, cuando se refiere a que la competencia podrá ser excluida mediante un acuerdo de elección de foro a favor de un tribunal extranjero. Cualquier efecto diferente de esta exclusión entendemos que debería especificarse en el acuerdo.

37. La sumisión a los tribunales españoles no se supedita a la existencia de vínculos con nuestro país, por lo que habría que considerar que tampoco se requerirán vínculos con el tribunal extranjero elegido ${ }^{68}$. Esta libertad queremos ponerla en relación con la línea jurisprudencial a la que anteriormente nos referíamos, en el sentido de rechazar la derogatio fori cuando la plantea el demandado domiciliado en nuestro país, por considerar que se trataría de un abuso de derecho prohibido por el art. 11.2 LOPJ, dado que lo más beneficioso para este demandado se supone que es litigar ante los tribunales de su domicilio.

38. Tal interpretación ignora que las partes llegaron a un acuerdo para litigar ante unos determinados tribunales y que el demandado puede estar interesado en mantener la vigencia de dicho acuerdo por razones vinculadas al derecho material o procesal aplicable ${ }^{69}$. La doctrina se ha decantado por ello de forma prácticamente unánime en contra de dicha línea jurisprudencial, señalando que el abuso de derecho solo podría apreciarse en circunstancias muy excepcionales ${ }^{70}$. En cuanto a cuáles podrían ser esas circunstancias excepcionales hemos de señalar que el Convenio de La Haya de 30 de junio de 2005 sobre acuerdos de elección de foro contempla algunas situaciones en las que no operaría la derogatio fori, que podrían servir de modelo. Su art. 6.c) se refiere a situaciones de manifiesta injusticia o de contrariedad con el orden público del tribunal ante el que se ha acudido y su art. 6.d) a causas excepcionales que fueran más allá del control de las partes, que aparecen ejemplificadas en el Informe que acompaña al Convenio quedando de manifiesto que se trata de circunstancias muy excepcionales ${ }^{71}$.

68 Esta afirmación debe matizarse en relación con el sector del Derecho de familia y sucesiones si se toman como modelo los Reglamentos de la UE para admitir la derogatio fori (véase párr. 34), dado que dichos Reglamentos sí establecen límites en relación con la elección del tribunal competente.

69 Esteban DE la Rosa, F., op. cit., nota 21, p. 293; Garcimartín AlfÉrez, F. J., se ha referido a argumentos relacionados con el fundamento contractual de la cláusula de elección de foro, así como a razones de eficiencia para descartar el abuso de derecho salvo en circunstancias muy excepcionales, op. cit., nota 3, pp. 111 y ss.

70 Álvarez González, S., op. cit., nota 23, pp. 378 y ss.; Calvo Caravaca, A. L. y Carrascosa GonzáLEZ, J., op. cit., nota 26, pp. 387-388; GARAU Sobrino, F., op. cit., nota 44, p. 194.

${ }^{71}$ En el Informe explicativo del Convenio se señala que en el art. 6.c) quedarían comprendidas las situaciones en que una de las partes no pudiera obtener un procedimiento justo en el Estado extranjero, quizás por parcialidad o corrupción, o porque existieran otros motivos concretos relacionados con esa parte que le impidieran incoar un procedimiento o defenderse en un procedimiento ante el tribunal elegido; y como ejemplo de situaciones que quedarían comprendidas en el art. 6.d) se alude a que hubiera una situación de guerra en el Estado al que pertenece el tribunal elegido o a que el tribunal elegido hubiera dejado de existir o hubiera cambiado tan profundamente que no se le pudiera seguir considerando como el mismo tribunal que eligieron las partes, Hartley, T. y Dogauchi, M., Informe explicativo del Convenio de 30 de junio de 2005 sobre acuerdos de elección de foro, editado por la Oficina Permanente de la Conferencia, http://www.hcch.net (consultada el 19 de octubre de 2017), p. 51. 


\subsection{La validez formal del acuerdo}

39. El art. 22 bis.2 LOPJ dispone que el acuerdo de sumisión expresa «deberá constar por escrito, en una cláusula incluida en un contrato o en un acuerdo independiente, o verbalmente con confirmación escrita, así como en alguna forma que se ajuste a los hábitos que las partes tengan establecidos entre ellas, o en el comercio internacional sea conforme a los usos que las partes conozcan o deban conocer y que, en dicho comercio, sean ampliamente conocidos y regularmente observados por las partes en los contratos del mismo tipo en el sector comercial considerado. Se entenderá que media acuerdo escrito cuando resulte de una transmisión efectuada por medios electrónicos que proporcione un registro duradero».

40. Como cabe observar, se trata de una formulación claramente inspirada en el Reglamento 1215/2012 $2^{72}$, que difícilmente tendrá operatividad en lo que a la sumisión de las partes a nuestros tribunales se refiere, dado su carácter subsidiario. Entendemos que sí debe servirnos no obstante para apreciar que las partes se han sometido válidamente a un tribunal extranjero a efectos de que opere la derogatio for ${ }^{73}$. Dichos requisitos de forma son fruto de una evolución normativa, que ha venido determinada en buena medida por la jurisprudencia del TJUE, con la que se ha tratado de encontrar un equilibrio entre los intereses derivados del comercio internacional, que exigen huir de excesivos formalismos, y el principio de seguridad jurídica, que exige garantizar que el consentimiento de las partes efectivamente se ha prestado ${ }^{74}$. Como ya han sido amplia y exhaustivamente analizados a propósito del Reglamento 1215/2012 no vamos a entrar aquí en su análisis, limitándonos a reflexionar sobre dos aspectos que nos resultan interesantes en relación con la derogatio fori.

41. Como veíamos en el epígrafe anterior, el acuerdo de sumisión expresa, a los tribunales españoles o a los tribunales extranjeros, se basa en un pacto entre las partes (art. 22 bis. 2 LOPJ). La jurisprudencia del TJUE a propósito de los requisitos de validez formal ha venido vinculando su cumplimiento con la existencia del consentimiento, desde sus primeras decisiones sobre el Convenio de Bruselas de 27 de septiembre de 1968. Como el Regla-

72 El art. 22 bis. 2 LOPJ dispone también que «se considerará igualmente que hay acuerdo escrito cuando esté consignado en un intercambio de escritos de demanda y contestación dentro del proceso iniciado en España, en los cuales la existencia del acuerdo sea afirmada por una parte y no negada por la otra». Esta precisión adicional, que se aparta de lo dispuesto en el Reglamento 1215/2012, ha sido justamente criticada por la doctrina señalando que si este acuerdo se produce intra processum estaríamos en realidad ante un supuesto de sumisión tácita, Calvo CARAVACA, A. L. y CARRascosa GonZÁlez, J., op. cit., nota 26, p. 363; GARCimartín AlfÉrez, F. J., op. cit., nota 55, p. 5.

${ }^{73} \mathrm{Al}$ igual que señalamos en el epígrafe anterior, si se toman como modelo los Reglamentos de la UE para admitir la derogatio fori en materia de Derecho de familia y sucesiones, habría que considerar que en estos Reglamentos los requisitos formales son más estrictos.

74 Rodríguez Benot, A., "Art. 25», en Blanco-Morales Limones, P., Garau Sobrino, F., Lorenzo Guillén, M. L. y Montero Muriel, F. J. (coords.), Comentario al Reglamento (UE) núm. 1215/2012 relativo a la competencia judicial, el reconocimiento y la ejecución de resoluciones judiciales en materia civil y mercantil, Cizur Menor, Thomson Reuters, 2016, p. 565. 
mento 1215/2012 ha introducido una solución para las cuestiones de validez material, se ha planteado cuál debía ser el ámbito de aplicación de este nueva disposición y si debía extenderse a la existencia del consentimiento. La doctrina ha sido prácticamente unánime al señalar que la línea interpretativa del TJUE no debía verse afectada y que el consentimiento debía seguir deduciéndose del cumplimiento de los requisitos formales ${ }^{75}$. Se añade que esta interpretación se ha confirmado en dos recientes sentencias del TJUE, que aunque referidas al Reglamento 44/2001, tienen el interés añadido de que mantienen la interpretación anterior en un contexto en el que el Reglamento $1215 / 2012$ ya se encuentra vigente - Sentencia del TJUE de 7 de julio de 2016, Höszig, as. C-222/15 (p. 38) ${ }^{76}$ y de 28 de junio de 2017, Leventis y Vafias, asunto C-436/16 (p. 34$)^{77}$ -

42. Tal interpretación pensamos que se extenderá a nuestra LOPJ a efectos de apreciar que existe el acuerdo de las partes en favor de un tribunal extranjero, dado que el art. 22 bis. 2 LOPJ es una copia de lo dispuesto en el Reglamento 1215/2012. Y como la aplicación de esta normativa se ha interpretado en la práctica de forma muy flexible, especialmente cuando se ha hecho referencia a los usos del comercio internacional, puede suceder que desde la perspectiva del tribunal extranjero elegido se considere que el acuerdo no es válido, si tiene criterios más restrictivos a este respecto. Recuérdese que estamos analizando los acuerdos de sumisión expresa en favor de tribunales de Estados extranjeros, con los que carecemos de una normativa uniforme y común.

43. El segundo aspecto sobre el que queríamos reflexionar está relacionado con el anterior. Como es bien sabido, la Sentencia del TJCE de 16 de marzo de 1999, Castelleti, asunto C-159/978, se refirió a los usos del comercio internacional para pronunciarse en favor de la validez de una cláusula de sumisión expresa inserta por una de las partes en un conocimiento de embarque. A nivel interno, nuestra jurisprudencia se ha referido también en numerosas ocasiones a esta modalidad de validez formal en relación con este mismo supuesto, llegando a igual resultado ${ }^{79}$.

75 Entre otros, Magnus, U., «Sonderkollisionsnorm für das Statut von Gerichtsstands- und Schiedsgerichtverinbarungen?», IPRax, 2016, núm. 6, pp. 521-531, esp. p. 523; GARCIMARTÍN ALFÉREZ, F. J, "Prorogation of Jurisdiction», en Dickinson, A. y LeIN, E. (eds.), The Brussels I Regulation Recast, Oxford, Oxford University Press, 2015, p. 293; Herranz Ballesteros, M., «The Regime of Party Autonomy in the Brussels I Recast: the Solutions Adopted for Agreements on Jurisdiction ", Journal of Private International Law, vol. 10, 2014, núm. 2, pp. 291-308, esp. p. 302.

76 ECLI:EU:C:2016:525.

77 ECLI:EU:C:2017:497.

78 ECLI:EU:C:1999:142. nota de RodRíguez BenOT, A., REDI, 1999, núm. 2, pp. 701 y ss.

79 A modo de ejemplo véase Sentencia de la AP de Barcelona (Sección 15. ${ }^{\text {) }}$, de 20 de septiembre de 1999, AEDIPr, t. I, 2001, con nota de Miguel Asensio, P. A., pp. 888-901 y de Rodríguez Benot, A., $R E D I$, vol. LII, 2000, núm. 2, pp. 568-573; Sentencia de la AP de Valencia de 18 de octubre de 2000, $A E-$ $D I P r$, t. II, 2002, con nota de Álvarez Rubio, J. J., pp. 609-618; Sentencia de la AP Cádiz de 28 de mayo de 2001 y Auto de la AP Cádiz de 10 de septiembre de 2001, AEDIPr, t. III, 2003, con nota de FACH GóMEZ, K., pp. 805-820; Sentencia de la AP de Pontevedra (Sección 5. ${ }^{\text {) }}$, de 14 de enero de 2002 y Sentencia de la AP de Cantabria (Sección 4. ${ }^{\text {) }}$, de 10 de julio de 2002, AEDIPr, t. IV, 2004, con nota de Esteve 
44. Pues bien, la reciente Ley 14/2014, de 24 de julio, de Navegación Marítima ${ }^{80}$, pretende poner fin a tal interpretación a través de su art. 468 , que establece lo siguiente: «Sin perjuicio de lo previsto en los convenios internacionales vigentes en España y en las normas de la Unión Europea, serán nulas y se tendrán por no puestas las cláusulas de sumisión a una jurisdicción extranjera o arbitraje en el extranjero, contenidas en los contratos de utilización del buque o en los contratos auxiliares de la navegación, cuando no hayan sido negociadas individual y separadamente. En particular, la inserción de una cláusula de jurisdicción o arbitraje en el condicionado impreso de cualquiera de los contratos a los que se refiere el párrafo anterior no evidenciará, por sí sola, el cumplimiento de los requisitos exigidos en el mismo» ${ }^{81}$.

45. Este precepto se aplica en defecto de norma internacional. En el caso de que las partes se hubieran sometido a los tribunales de un Estado miembro de la UE se aplicará el art. 25 del Reglamento 1215/2012 ${ }^{82}$, sin que la interpretación que ha ido desarrollando el TJUE debiera verse afectada por el mencionado art. 468. Pero en el caso de que las partes se hubieran sometido a los tribunales de un tercer Estado sí sería relevante, de modo que el requisito de que hayan sido negociadas individual y separadamente supondría que no bastaría para su validez con la mera inserción del acuerdo de sumisión por una de las partes en el clausulado impreso de un contrato y la consiguiente apelación a los usos del comercio internacional ${ }^{83}$.

GonZÁlez, L., pp. 732-757; Auto de la AP Cádiz (Sección 7. a), de 22 de diciembre de 2003, AEDIPr, t. V, 2005, con nota de Garau Sobrino, F., pp. 604-617; Sentencia del TS (Sala de lo Civil, Sección 1. a), de 29 de septiembre de 2005, AEDIPr, t. VI, 2006, con nota de Fuentes CAMACHo, V., pp. 838-848; Auto de la AP de Madrid (Sección 28. ${ }^{\text {a }}$ ), de 23 de abril de 2010, AEDIPr, t. X, 2010, pp. 1048-1051; Auto de la AP de Madrid (Sección 28. ${ }^{\text {) }}$, de 17 de octubre de 2011, AEDIPr, 2011, t. XI, pp. 1096-1098.

80 BOE núm. 180, de 25 de julio de 2014.

81 El sector asegurador ha influido en la reforma que incorpora la Ley de Navegación Marítima, pues en los litigios relativos a la validez de los acuerdos de elección de foro insertos en un conocimiento de embarque suele aparecer como parte involucrada una aseguradora, subrogada en los derechos de una de las partes originarias del contrato. A los intereses del sector asegurador obedece el art. 251 de la Ley, conforme al cual el adquirente del conocimiento de embarque adquirirá todos los derechos y acciones del transmitente sobre las mercancías, excepción hecha de los acuerdos en materia de jurisdicción y arbitraje, que requerirán el consentimiento del adquirente en los términos señalados en el Capítulo I del Título IX; así como el referido art. 468 de la Ley, que es al que se remite desde el art. 251, que trata de evitar el automatismo con que los jueces españoles han venido vinculando la existencia y validez del acuerdo con los usos del comercio internacional. Véase SÁnchEZ-Horneros AdÁn, A. M., «La Ley 14/2014, de 24 de julio, de navegación marítima: última llamada para la jurisdicción española en asuntos marítimos», Diario La Ley, de 13 de julio de 2016, núm. 8802, pp. 1-14.

82 La misma consideración debe hacerse en relación con otros convenios internacionales, particularmente, el Convenio de Lugano de 30 de octubre de 2007, que es prácticamente idéntico. En relación con el Convenio de La Haya de 30 de junio de 2005 debe tenerse en cuenta que en su art. 2.f) excluye de su ámbito de aplicación el transporte de personas y de mercaderías.

83 En este sentido Álvarez Rubio, J. J., «La dimensión procesal internacional en la Ley de navegación marítima», $A E D I P r$, t. XIV-XV, 2014-2015, pp. 159-203, esp. p. 177. En palabras de GóMEZ JENE, M., el art. 468 de la Ley de Navegación Marítima eleva excesivamente el nivel de seguridad jurídica en este ámbito, desmarcándose de las tendencias legislativas y jurisprudenciales más modernas que, sin renunciar a un estándar mínimo de seguridad jurídica, intentan encontrar un punto de equilibrio entre esa seguridad y el principio de favor negotii, «Las cláusulas de jurisdicción y arbitraje en la nueva Ley de Navegación Marítima», Cuadernos de Derecho Transnacional, 2014, núm. 2, pp. 112-129, esp. p. 114. 
46. Esta decisión de nuestros tribunales en nada influiría la decisión del tribunal extranjero elegido, lo cual podría generar un escenario de una cierta complejidad procesal si este órgano tuviera, en relación con esta materia, unos criterios más permisivos ${ }^{84}$. Como ya hemos señalado, nos movemos en un entorno de falta de uniformidad jurídica, con lo que la apreciación de los tribunales de los distintos Estados vinculados con la relación jurídica sobre la validez del acuerdo de sumisión puede variar. Se añade, como factor de complejidad adicional, que el art. 468 de la Ley de Navegación Marítima aboca a nuestros tribunales a proceder de forma diversa en función de cuál sea el Estado a cuyos tribunales se han sometido las partes, lo cual no parece que vaya a ser tarea fácil ${ }^{85}$. No hay que descartar que este precepto acabe generando una interpretación más restrictiva en relación también con el Reglamento 1215/2012. De momento nuestra jurisprudencia, aunque escasa y por tanto poco significativa, no muestra que vaya a ser así. Cabe referirse a dos Autos de la AP de Valencia, de 8 de noviembre de $2016^{86}$ y de 15 de mayo de $2017^{87}$, donde se diferenció entre el acuerdo de sumisión a favor de un Estado miembro y de un tercer Estado, para justificar que en este último caso sí cabía hacer una interpretación más restrictiva al amparo del art. 468 de la Ley de Navegación Marítima.

\subsection{La validez material del acuerdo}

47. El art. 22 bis.2 LOPJ dispone que la competencia establecida por sumisión expresa se extenderá a la propia validez del acuerdo de sumisión. En relación con este párrafo se ha señalado que la validez solo puede ser enjuiciada por los tribunales españoles, cuestionando que quién si no iba a enjuiciarla, y que ello debe ser así tanto en relación con el efecto prorrogatorio como derogatorio del acuerdo, a pesar del silencio del art. 22 ter.4 LOPJ a este respecto ${ }^{88}$.

48. Considerando la influencia que el Reglamento $1215 / 2012$ ha tenido en la reforma de la LOPJ, esa referencia a la competencia del órgano jurisdiccional elegido para pronunciarse sobre la validez del acuerdo, entendemos que puede relacionarse con la autonomía que tiene este acuerdo con respecto al contrato en el que normalmente se contiene - su validez se contempla específicamente para hacer competente al tribunal elegido-, y que ese pronunciamiento debe englobar también las cuestiones de validez material.

49. Conforme al art. 25 del Reglamento 1215/2012, el tribunal elegido será competente, a menos que el acuerdo sea nulo de pleno Derecho en cuan-

${ }^{84}$ Miguel Asensio, P., «Los acuerdos de jurisdicción en la nueva Ley de navegación marítima», blog http://pedrodemiguelasensio.blogspot.com.es, entrada el 9 de octubre de 2014 (consultado por última vez el 14 de octubre de 2017).

85 Álvarez Rubio, J. J., op. cit., nota 83, p. 180.

86 Consultada en CENDOJ, ECLI:ES:APV:2016:607A.

87 Consultada en CENDOJ, ECLI:ES:APV:2017:1811A.

88 Garcimartín AlfÉrez, F. J., op. cit., nota 55, p. 5. 
to a su validez material según el Derecho del Estado miembro elegido, lo cual incluirá sus normas sobre conflicto de leyes (cdo. 20). Se trata de una norma uniforme de remisión, inspirada en el Convenio de La Haya de 30 de junio de 2005 sobre acuerdos de elección de foro ${ }^{89}$, con la que se ha introducido una respuesta para las cuestiones de validez material de la que antes carecía el Reglamento. Es de suponer que el art. 22 bis. 2 LOPJ pretendiera referirse también a la validez material y, de hecho, su formulación en clave unilateral llevaría en la práctica a la misma consecuencia jurídica que el Reglamento: la validez material se decidiría conforme al Derecho español por el tribunal español que ha sido elegido.

50. De aceptarse la aplicación de esta misma solución en relación con la derogatio fori supondría que la validez material del acuerdo de sumisión habría de resolverse conforme al Derecho del tribunal extranjero elegido, incluyendo sus normas de conflicto ${ }^{90}$. Se trataría de una solución beneficiosa desde el punto de vista de la seguridad jurídica, pues se llegaría a la misma conclusión sobre la validez material del acuerdo que el tribunal supuestamente elegido. No obstante, su aplicación en la práctica, incluso en relación con los instrumentos internacionales que la recogen expresamente, nos suscita interrogantes dada su complejidad: al dato de que habrá de aplicarse un Derecho extranjero, con la influencia que la actuación de las partes a este respecto pudiera tener, se añade que las soluciones previstas en dicho Derecho extranjero para la validez material de los acuerdos de sumisión expresa pueden ser poco claras o inexistentes - como muestra nuestro ordenamiento, donde se propone una aplicación analógica de lo dispuesto en el Reglamento 593/2008 (Roma I), que excluye esta materia de su ámbito de aplicación [art. 1.2.e) $]^{91}$.

\subsection{Tratamiento procesal}

52. La parte demandada ante nuestros tribunales que quiere que se respete el acuerdo de sumisión expresa en favor de un tribunal extranjero debe plantear una cuestión de competencia judicial internacional. Si el deman-

$89 \mathrm{Al}$ respecto véase BEAUMONT, P. y YÜRSEL, B., «The Validity of Choice of Court Agreements under the Brussels I Regulation and the Hague Choice of Court Agreements Convention», en Boele-WoELKI, K., Einhorn, T., Girsberger, D. y Symeonides, S. (eds.), Convergence and Divergence in Private International Law. Liber amicorum K. Siehr, Zurich, Schulthess, 2010, pp. 563-577; UsUNIER, U., "Le droit applicable à la validité des clauses attributives de juridiction en vertu de l'article 25.1 du Règlement Bruxelles I bis», en AfFAKI, G. y Grigera NAON, H., Jurisdictional Choices in Times of Troubles, París, International Chamber of Commerce, 2015, pp. 158-176.

${ }_{90}$ Cuando se alude a cuestiones de validez material en el marco del Reglamento 1215/2012 se consideran los posibles vicios del consentimiento. La inclusión de las cuestiones de capacidad que pudieran afectar a la validez material del acuerdo de elección resulta más dudosa, considerando la exclusión de esta materia en relación con las personas físicas [art. 1.2.a)].

91 Reglamento (CE) núm. 593/2008, del Parlamento Europeo y del Consejo, de 17 de junio, sobre la ley aplicable a las obligaciones contractuales (Roma I), DO L núm. 177, de 4 de julio de 2008; CALVO Caravaca, A. L. y Carrascosa González, J., op. cit., nota 26, pp. 258-259. 
dado comparece y contesta a la demanda se estaría sometiendo tácitamente a nuestros órganos jurisdiccionales. El demandado podría no comparecer. Pero en este caso hay que recordar que la derogatio fori se refiere a la actuación de nuestros tribunales en supuestos en los que tienen competencia judicial internacional, por lo que conforme a lo dispuesto en los arts. 36 y 38 LEC no procedería la abstención de oficio. Como se ha señalado además en relación con la polémica en torno a si en el marco del Reglamento 1215/2012 los acuerdos de sumisión expresa se controlan de oficio o a instancia de parte, si el interesado no lo alega, puede que el tribunal ni siquiera llegue a ser conocedor de que existe un acuerdo de sumisión en favor de los tribunales de otro Estado, dado que la información de la que dispondrá se limitará a la que le haya suministrado el demandante ${ }^{92}$.

53. La LOPJ ha introducido una peculiaridad en el tratamiento procesal. Tras señalar que la «competencia podrá ser excluida mediante un acuerdo de elección de foro a favor de un tribunal extranjero, añade que los tribunales suspenderán el procedimiento y solo podrán conocer de la pretensión deducida en el supuesto de que los Tribunales extranjeros designados hubieren declinado su competencia». En nuestro ordenamiento las cuestiones de competencia judicial internacional se plantean a través de la declinatoria (arts. 63 y ss. LEC) ${ }^{93}$, donde se prevé, si el tribunal entendiese que carece de jurisdicción por corresponder el conocimiento del asunto a los tribunales de otro Estado, que lo declare mediante auto, absteniéndose de conocer y sobreseyendo el proceso. Conforme a la LOPJ, la posibilidad de que los tribunales españoles pudieran ejercer finalmente su competencia quedaría en suspenso, merced a lo que decidiese un tribunal extranjero.

54. Tal disposición presenta como ventaja que al operar en un marco normativo caracterizado por la ausencia de uniformidad jurídica, tiene en cuenta que el órgano jurisdiccional supuestamente elegido puede considerar que el acuerdo no es válido. Su aplicación en la práctica puede plantear no obstante problemas, debido al carácter indefinido del plazo de suspensión, pues no se fija límite temporal alguno ${ }^{94}$. En este sentido, ante la posibilidad de que un tribunal extranjero se demorase excesivamente produciendo indefensión, sería conveniente ofrecer una solución inspirada en las normas sobre litispendencia y conexidad con terceros Estados, donde también está prevista la suspensión del procedimiento ante nuestros tribunales, con la salvedad de que podría retomarse su desarrollo si no se observa que el tribunal extranjero pueda concluir en un tiempo razonable ${ }^{95}$.

92 Garau Sobrino, F., op. cit., nota 44, pp. 129-130; Kramer, X., «Art. 28», en Dickinson, A. y LeIN, E. (eds.), The Brussels I Regulation Recast, Oxford, Oxford University Press, 2015, pp. 317-318.

93 Ley 1/2000, de 7 de enero, de Enjuiciamiento Civil, BOE núm. 7, de 8 de enero de 2000.

94 Calvo Caravaca, A. L. y Carrascosa González, J., op. cit., nota 26, p. 386; Cordero Álvarez, C. I., op. cit., nota 56, pp. 113-114; Garcimartín AlFÉREZ, F. J., op. cit., nota 55, p. 5.

95 Véanse los arts. 33 y 34 del Reglamento $1215 / 2012$ y los arts. 39 y 40 de la Ley 29/2015, de 30 de julio, de cooperación jurídica internacional en materia civil, BOE núm. 182, de 31 de julio de 2015. 


\section{CONCLUSIONES}

55. La incorporación de una disposición a nuestra LOPJ sobre la derogatio fori debe ser bien recibida, porque da respuesta a una carencia que presentaba nuestro ordenamiento, en el sentido que ya había anticipado la doctrina y jurisprudencia. Se puede decir que con esta reforma se incorpora por fin a nuestro sistema autónomo una regulación completa de los efectos de los acuerdos de sumisión expresa, cuya regulación estaba limitada hasta ahora a la prorrogatio fori.

56. Se trata de una regulación aplicable en defecto de normativa internacional, que suscita no obstante numerosos interrogantes debido a las deficiencias técnicas que presenta. Del tenor del art. 22 ter LOPJ se desprende que la derogatio fori puede operar cuando nuestros tribunales resulten competentes en virtud del foro general del domicilio del demandado o de los foros especiales, pero la determinación de las materias concretas en relación con las que puede operar no está clara. El art. 22 ter LOPJ remite al art. 22 bis LOPJ, cuyo tenor literal carece de sentido, lo cual obliga a tratar de averiguar lo que quiso decir nuestro legislador. Con una adecuada reforma de la LOPJ, la cuestión referente a las materias en relación con las que se admite la derogatio fori debería haber quedado resuelta con total claridad.

57. En la reforma de la LOPJ se observa una fuerte influencia del Reglamento 1215/2012, tanto en relación con la definición que se hace de lo que es un acuerdo de sumisión expresa, como en la regulación de los requisitos de validez formal e, implícitamente, de validez material. La apreciación de la validez del acuerdo de sumisión expresa en favor de tribunales extranjeros puede inspirarse por ello en la abundante jurisprudencia del TJUE a propósito de estos acuerdos en el marco del Reglamento.

\section{RESUMEN}

\section{LA DEROGATIO FORI EN LA LEY ORGÁNICA DEL PODER JUDICIAL}

En este artículo se analiza el régimen de la derogatio fori tras la reforma de la Ley Orgánica del Poder Judicial. El artículo se centra en la actuación de los tribunales españoles de cara a verificar la existencia de un acuerdo de sumisión expresa a tribunales extranjeros, así como el control de su validez formal y material de cara a justificar la suspensión del procedimiento en nuestro país.

Palabras clave: derogatio fori, antecedentes, regulación, acuerdo de sumisión, validez formal y material.

\section{ABSTRACT \\ THE DEROGATIO FORI IN THE JUDICIARY ORGANIZATION ACT}

This article deals with the regulation of the derogatio fori after the amendment of the Ley Orgánica del Poder Judicial (Judiciary Organization Act). The article focuses on the 
way our tribunals should act to verify that the parties have agreed to submit the dispute to a foreign tribunal and that such agreement is valid from a formal and substantive perspective, in order to stay the proceedings in our country.

Keywords: derogatio fori, precedents, regulation, choice of court, formal and substantive validity. 